\title{
The prediction of the methane production in landfill affected by the temperature
}

\author{
Lianying Zhou ${ }^{1}$, Juan Liao $^{2}$, Houbin Fan ${ }^{3}$, Lixin Liüand Miaomiao Sun ${ }^{5}$ \\ ${ }^{1}$ Zhejiang University City College, Hangzhou 310015, China \\ ${ }^{2}$ Zhejiang University City College, Hangzhou 310015, China \\ ${ }^{3}$ Zhejiang Zhoushan Cross-Sea Bridge Co., Ltd., Zhoushan 316031, China \\ ${ }^{4}$ School of Automobile and Transportation, Qingdao Technological University, 266520, China \\ ${ }^{5}$ Zhejiang University City College, Hangzhou 310015, China
}

\begin{abstract}
The functional relationship between the generation rate coefficient and temperature was developed for quantitative prediction of the temperature effect in this paper. The methane production of the landfill was predicted under the condition of the seasonal variation. The results showed that considering the temperature effect, the methane production is higher than the methane production without temperature effect of the $0.14 \times 106 \mathrm{~m} 3 \sim 0.28 \times$ $106 \mathrm{~m} 3$.With the depth increasing, the effect of the atmospheric temperature fluctuation on the temperature change of the landfill was weakened. The temperature has a significant effect on the methane production in the landfill. The temperature effect should be considered when simulate the long time effect of the landfill methane production.
\end{abstract}

\section{Introduction}

It is important to study the prediction of methane production in landfill for landfill gas reuse. The prediction results will provided the evidence for the operation of the power.

The methane generation in landfill was usually described by the experimental and numerical investigations. Heejun Suk(2000)proposed the gas transport model includes the microbial growth and death, and aerobic and anaerobic biodegradation ${ }^{[1]}$. G. De Gioannis et al. (2009) investigated the estimation of the variation of the potential gas generation capacity L0 by mechanical biological treatment of $\mathrm{MSW}^{[2]}$. Shirley Thompson et al.(2009) modified the parameters of the gas generation model such as the German EPER, TNO, Belgium, LandGEM and Scholl Canyon model for 36 landfills in $\mathrm{Canada}^{[3]}$.

The potential heat exportation capacity is described by the bio-chemical theory. El-Fadel et al.(1996 a) proposed the heat generation rate function described by the acetic acid net generation rate ${ }^{[4]}$. Veeken $A$. and Hamelers B.(1999) presented the effect of the temperature on the hydrolysis rate of the waste. The combustion organism is the other effective method to test the value of the heat release ${ }^{[5]}$. Liu (2011) et al report the elevation of the temperature have a significantly

\footnotetext{
${ }^{a}$ Corresponding author: author@e-mail.org
}

influence on the organic matter decomposition leading to accelerate the gas generation in bioreactor ${ }^{[6]}$.

Therefore, in this paper, the gas generation rate model which considered the temperature effect was given, simulating the law of the gas production under the influence of temperature in different depths. And the gas productions of methane under the consideration of the temperature effect or not were compared and analyzed.

Please note that the first line of text that follows a heading is not indented ("p1a" style).

The first lines of all subsequent paragraphs are ("Normal" style).

\section{Mathematical Model}

The methane production was described by the equation.

$$
R=k(T) Q_{0} \cdot e^{-k(T) t}
$$

Where, $\mathrm{K}$ is the generation rate coefficient, related to the temperature, $\mathrm{k}(\mathrm{T})$. When the temperature effect was ignored, it will be constant. $\mathrm{Q}_{0}$ is the initial production potential. 
The coupling function of the change of the gas generation and the temperature may be developed by the Arrhenius equation (MIROSLAV NASTEV(1998) ${ }^{[7]}$ ),

$$
k(T)=k_{0} \cdot \exp \left(-E_{a} / R T\right)
$$

Where, $\mathrm{K} 0=$ constant. $\mathrm{R}=$ mole gas constant, $8.314(\mathrm{~J}$ mol-1 K-1). Ea=activation energy $(\mathrm{kJ}$ mol-1). $\mathrm{T}$ is the temperature. follow,

The heat flux in landfill could be expressed by the

$$
F_{i}=-\lambda \cdot \nabla T
$$

Where, $\nabla T$ is the temperature gradient. $\lambda$ is the thermal conductivity.

The atmospheric temperature monitoring data of a city in China was the basis of the seasonal variation parameter for obtaining the effect of the external environment on the temperature distraction in the landfill. Calculation parameters were shown in Table 1.1.

$$
T_{t}=T_{m}-A_{s} \cos \left[\frac{2 \pi}{365}\left(t-t_{0}\right)\right]
$$

Where, Tm represented the average annual temperature $\left({ }^{\circ} \mathrm{C}\right)$ in the region which took $23{ }^{\circ} \mathrm{C}$. As represented the amplitude of surface temperature fluctuations $\left({ }^{\circ} \mathrm{C}\right.$ )which took $18{ }^{\circ} \mathrm{C} . \mathrm{t}_{0}$ represented the coefficient of the phase which took 35 days.

Table 1 Parameter of numerical simulation

\begin{tabular}{|c|c|}
\hline Parameter & Value \\
\hline Thermo-conductivity of waste $\left(\mathrm{W} \mathrm{m}^{-1} \mathrm{~K}^{-1}\right)$ & 0.184 \\
\hline Thermo-conductivity of cover $\left(\mathrm{W} \mathrm{m}^{-1} \mathrm{~K}^{-1}\right)$ & 55 \\
\hline Specific heat of waste $\left(\mathrm{J} \mathrm{kg}^{-1} \mathrm{~K}^{-1}\right)$ & 1333 \\
\hline Specific heat of cover $\left(\mathrm{J} \mathrm{kg}^{-1} \mathrm{~K}^{-1}\right)$ & 1406 \\
\hline Thermo-conductivity of gas $\left(\mathrm{W} \mathrm{m}^{-1} \mathrm{~K}^{-1}\right)$ & 0.03 \\
\hline Specific heat of gas $\left(\mathrm{J} \mathrm{kg}^{-1} \mathrm{~K}^{-1}\right)$ & 2215 \\
\hline Porosity & 0.5 \\
\hline Permeability of cover $\left(\mathrm{m}^{2}\right)$ & $1.0 \times 10^{-13}$ \\
\hline Cover thickness $(\mathrm{m})$ & 1 \\
\hline Permeability of waste $\left(\mathrm{m}^{2}\right)$ & $3.0^{\circ} \times 10^{-12}$ \\
\hline
\end{tabular}

\section{Results and Discusstion}

The capabilities of producing methane of the landfill under the considering the temperature or not were compared and analyzed (coupling and non-coupling). Simulation time was 1 year. The results were as shown in Fig. $3.1 \sim 3.6$.
The results showed that the refuse which was near the surface was influenced bigger by the outside temperature. And the temperature of the refuse had a bigger fluctuation. As a result, the gas production appeared to fluctuate. In summer, the gas production was higher because of the higher temperature. In winter, the gas production was lower because of the lower temperature. The fluctuation of the gas production tended to delay with the depth increasing.

The outside temperature had no effect when the landfill depth reached below $10 \mathrm{~m}$. The change of the refuse temperature was mainly determined by its own biochemical degradation and exothermic. The temperature continuing to rise was because of the degradation was carried out continuously. As a result, the gas production of the landfill which considered the degradation was higher than the gas production of the landfill without considering the degradation. The difference of the gas production of single annual was about $0.14 \times 10^{6} \mathrm{~m}^{3} \sim 0.28 \times 10^{6} \mathrm{~m}^{3}$.

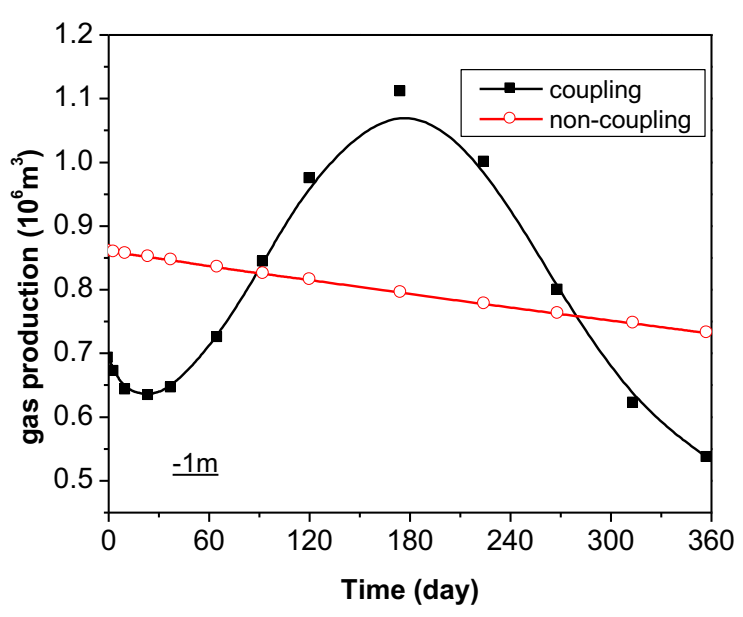

Figure 1 Compared with the methane production of the coupling and non-coupling temperature, $-1 \mathrm{~m}$

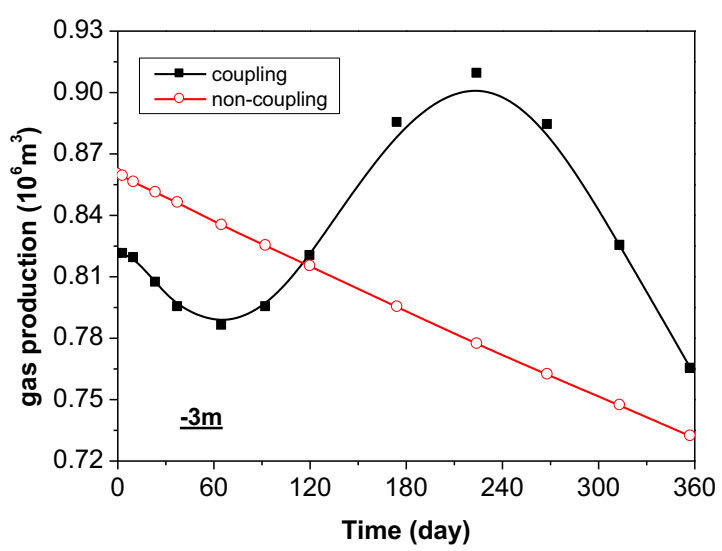

Figure 2 Compared with the methane production of the coupling and non-coupling temperature, $-3 \mathrm{~m}$ 


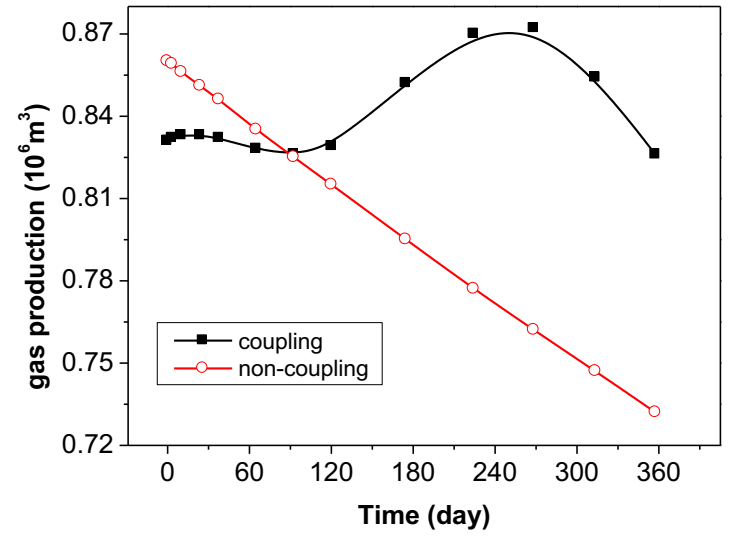

Figure 3 Compared with the methane production of the coupling and non-coupling temperature, $-5 \mathrm{~m}$

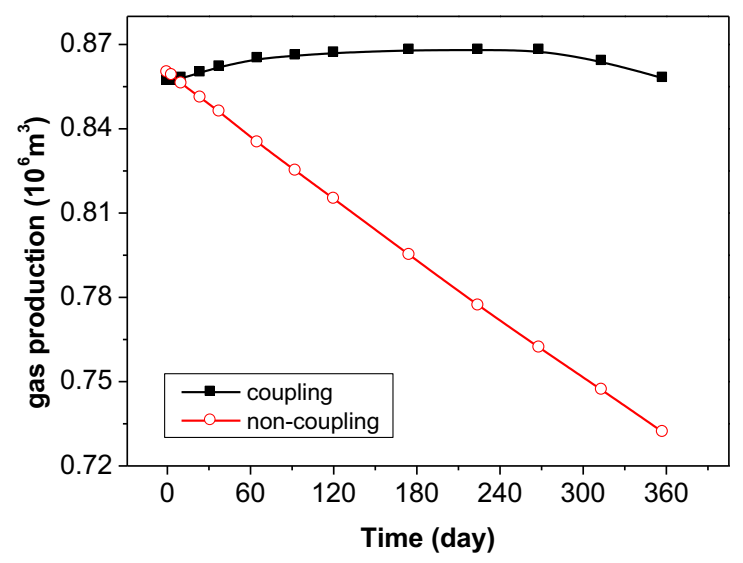

Figure 4 Compared with the methane production of the coupling and non-coupling temperature, $-10 \mathrm{~m}$

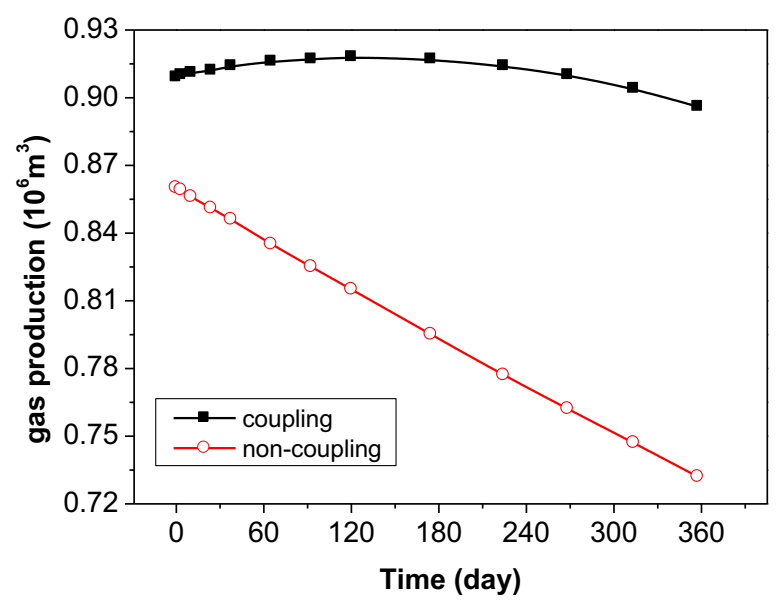

Figure 5 Compared with the methane production of the coupling and non-coupling temperature, $-20 \mathrm{~m}$

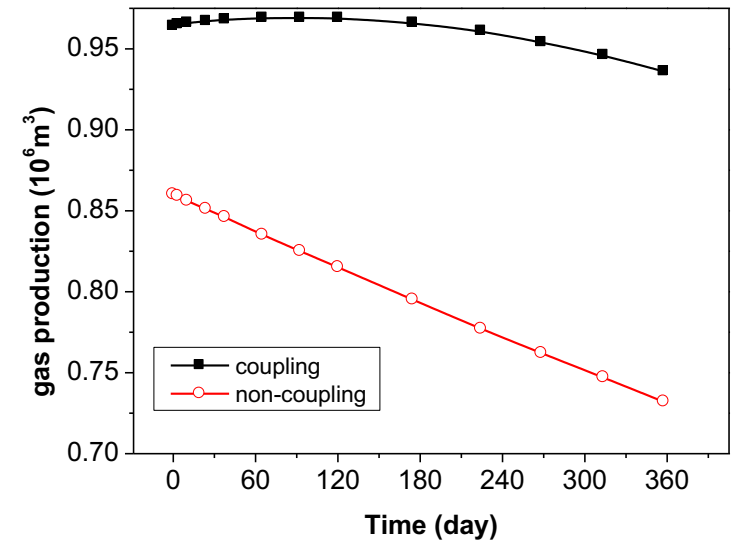

Figure 6 Compared with the methane production of the coupling and non-coupling temperature, $-30 \mathrm{~m}$

\section{Conclusions}

The methane production was impacted by the variation of the temperature in landfill. As results of the difference of the temperature between the inside and the outside of the landfill, the temperature and the gas generation rate of the waste were obviously varied with the season. There are comparatively difference between the coupled model and non-coupled model of the simulation results about gas production volume. Therefore, the contribution of the temperature on the methane production in atmosphere should be considered in the long-term prediction.

\section{References}

1. Hee jun Suk, Kangkun Lee, Cheol Hyo LeeBiologically reactive multispecies transport in sanitary landfill. Journal of environmental engineering, 126(5): 419 427(2000)

2. G. De Gioannis, A. Muntoni, G. Cappai, S. Milia.Landfill gas generation after mechanical biological treatment of municipal solid waste. Estimation of gas generation rate constants. Waste Management. 29 : 1026 1034(2009)

3. Shirley Thompson, Jennifer Sawyer, Rathan Bonam. Building a better methane generation model: Validating models with methane recovery rates from 35 Canadian landfills. Waste Management. 29: 2085 2091(2009)

4. El Fadel, M., Findikakis, A. N., and Leckie, J. O.. Numerical modeling of generation and transport of gas and heat in sanitary landfills: II. Model application. Waste Management \& Research, ISWA. 14, 537 551(1996)

5. Veeken A. and Hamelers B. Effect of temperature on hydrolysis rates of selected biowaste components. Bioresource technology. 69:249 254 (1999)

6. Liu Lei, Xue Qiang, Liang Bing, et al. The modelling of biochemical-thermal coupling effect on gas 
generation and transport in MSW landfill. International Journal of Environment and Pollution. 46(3/4),216-229(2011)

7. MIROSLAV NASTEV. Modeling Landfill Gas Generation and Migration in Sanitary Landfills and Geological Formations. Ph.D. UNIVERSITÉ LAVAL, Canada (1998) 